\title{
UTILIZAÇĀO DO SILICATO BIOQUIMICAMENTE MODIFICADO NO SISTEMA DE IMPERMEABILIZAÇÃO ESTUDO DE CASO DE UM EMPREENDIMENTO RESIDENCIAL EM BELO HORIZONTE
}

\author{
COUTINHO, LEONARDO \\ Engenheiro Civil Msc \\ UFRJ \\ RJ; Brazil \\ leonardo.coutinho@tecnorap.com.br
}

\section{RESUMO}

O presente trabalho tem como objetivo apresentar um estudo de caso de impermeabilização de uma laje multiuso de um empreendimento residencial localizado em Belo Horizonte, de aproximadamente $2.250 \mathrm{~m}^{2}$, contemplando, piscinas, deck molhado, jardins, quadra de tênis, quadra poliesportiva, áreas de lazer e áreas de uso comum. Utilizando o sistema de impermeabilização composto pricnipalmente pelo silicato bioquimicamente modificado, há um aumento na vida útil da impermeabilização para nível superior, segundo a NBR 15.575, pois esse material, por se tratar de uma reação química que não se degasta com o passar do tempo, permanece ativo por toda a vida útil da estrutura. Proporcionando sustentabilidade ao meio ambiente, menor tempo no isolamento da área tratada, os benefícios adquiridos nas condições internas da estrutura de concreto e a facilidade na necessidade de manutenabilidade da estrura caso necessário. $\mathrm{O}$ silicato bioquimicamente modificado se associa ao cálcio livre do concreto e toda vez que entra em contato com a umidade, reage quimicamente resultando na formação de um gel C-S-H dentro do concreto, que ao expandir veda poros vazios e capilares dentro da estrutura, protegendo e lhe impermeabilizando. Proporcionando desta forma propriedades regenerativas definitivas (auto-cicatrizantes), pois sua reação química dentro do concreto faz com que o gel C-S-H formado, se expanda conforme a estrutura necessite, ou seja, por formar um gel, a sua reação acompanha as características de porosidade e fissuração da estrutura, preenchendo os vazios necessários para proteção da estrutura de concreto. $\mathrm{O}$ aumento da vida útil, a grande melhoria na manutenabilidade e a sustentabilidade que esse sistema proporciona há mais de 40 anos nas estruturas de concreto armado, devem ser apresentados buscando o desenvolvimento da boa técnica na engenharia brasileira.

Palavras-chave: impermeabilização, silicato bioquimicamente modificado, proteção de concreto, mecanismos de degradação, manifestações patológicas.

\begin{abstract}
This paper aims to present a case study of waterproofing a multipurpose slab of a residential enterprise located in Belo Horizonte, approximately $2.250 \mathrm{~m}^{2}$, including swimming pools, wet deck, gardens, tennis court, sports court, leisure areas. and areas of common use. Using the waterproofing system with biochemically modified silicate, will increase the waterproofing life to a higher level, according to NBR 15.575, providing sustainability to the environment, less time in isolation of the treated area, the benefits gained the internal conditions of the concrete structure and the ease of maintenance of the structure if necessary. Biochemically modified silicate associates with the free calcium of the concrete and whenever it comes in contact with moisture, it reacts chemically resulting in the formation of a CSH gel inside the concrete, which by expanding seals empty and capillary pores within the structure, protecting and waterproofing the structure. Thus providing definitive regenerative properties (self-healing), because its chemical reaction within the concrete causes the formed $\mathrm{CSH}$ gel to expand as the structure needs, by forming a gel, its reaction follows the characteristics of porosity and cracking of the structure, filling the voids needed to protect the concrete structure. The increase in service life, the great improvement in maintainability and the sustainability that this system provides for over 40 years in reinforced concrete structures should be presented seeking the development of good technique in Brazilian engineering.

Keywords: waterproofing system, biochemicaly modified silicate, concrete protection, mechanism of degradation, pathological manifestation.
\end{abstract}




\section{INTRODUÇÃO}

A competitividade na industria da construção civil, principalmente relacionada à construção de empreendimentos residenciais e comerciais, está cada vez mais acirrada, portanto, a necessidade por redução de custos e produtividade são fatores primordiais para melhorar a relação do custo-benefício do empreendimento. Entretanto, a opção por um sistema de impermeabilização em detrimento de outro não pode se basear exclusivamente no caráter financeiro, pois cada sistema possui seus locais recomendados de aplicação, diferentes produtividades e cada sistema possui sua vida útil recomendada.

A fim de estabelecer e orientar aos projetistas na elaboração de projetos mais adequados à vida útil de cada sistema contrutivo utilizado nas edificações, a Associação Brasileira de Normas Técnicas (ABNT), desenvolveu uma normativa buscando estabelecer prazos de vida útil para os diversos sistemas construtivos (NBR 15.575, 2013). Desta forma, os projetos deverão obedecer as orientações técnicas apresentadas nessa normativa, buscando fazer com que os sistemas construtivos tenham a durabilidade compatível com a vida útil de projeto (VUP) preestabelecida.

Portanto o sistema de impermeabilização das estruturas construtivas deverá ser definido com base na sua vida útil e na área em que ele será utilizado. A definição de impermeabilização segundo a NBR 9575 (2010), é o conjunto de operações e técnicas, que protegem as construções contra a ação deletéria dos flúidos, de vapores e da umidade. $\mathrm{E}$ a definição de estanqueidade segundo a NBR 9575 (2010), é a capacidade de um elemento em impedir a penetração ou passagem de flúidos através de si.

Quando se trata de impermeabilização em estruturas de concreto armado, três são os fatores da microestrutura do concreto que influenciam diretamente no seu processo de degradação, são eles: a porosidade do concreto, o cálcio livre presente na estrutura após a hidratação do cimento e água proveniente do ambiente. Esses três fatores são responsáveis diretos por alguns efeitos deletérios nas estruturas de concreto, tais como: eflorescência, carbonatação e corrosão das armaduras.

Portanto, a fim de previnir os efeitos deletérios da água nas estruturas de concreto armado normalmente são utilizadas membranas acima da estrutura de concreto para sua proteção. A grande maioria dos sistemas de impermeabilização que utilizam membrana, necessitam, além da camada de impermeabilização (membrana), da regularização para que a impermeabilização possa ser aplicada acima dela, da camada separadora e de uma estrutura sobre a camada separadora para proteger a membrana, chamada proteção mecânica. Entretanto existem outros materiais de impermeabilização, que fazem parte de alguns sistemas de impermeabilização que são adicionados ao concreto, podendo ser adicionados no momento da concretagem da estrutura, como por exemplo com a adição de cristalizantes ou outros materiais que são adicionados após a cura do concreto, como por exemplo utilizando o silicato bioquimicamente modificado, que será estudado nesse estudo de caso.

\section{FUNDAMENTAÇÃO TEÓRICA}

A necessidade de proteção das estruturas de concreto armado é fundamental quando se pensa em vida útil da estrutura e do ambiente em que ela esteja inserida. QUERUZ (2007) afirma que a água é um dos principais agentes de degradação de forma direta ou indireta das estruturas de concreto armado.

Outro fator que deve ser levado bastante em consideração na estrutura de concreto armado é a sua porosidade, pois quando se analisa a durabilidade da estrutura, diversos autores entendem que o ensaio de compressão axial é um fator primordial a ser analisado e que através deste ensaio é possível entender melhor como está formada a composição física do concreto. Quanto maior for o valor de resistência à compressão axial menor tenderá a ser a sua porosidade e índice de vazios, mas . MOREIRA (2001), apresenta que a análise da resistência a compressão axial é fundamental, pois este é um fator primordial para qualquer estudo ligado ao ataque químico em estruturas de concreto, porque dependendo do tipo de ataque, pode comprometer até 60\% da capacidade dos corpos de prova de referência. HELENE (2003) apresenta a importância do estudo da resitência a compressão, da espessura do combrimento de concreto da armadura e da idade da estrutura, pois essas informações são importantes para analisar a exposição a um meio ambiente agressivo, 
fornecendo uma boa base de entendimento de como a estrutura está se comportando, caso a estrutura seja existente, ou como ela deverá se comportar, caso a estrutura seja recente ou esteja sendo construída.

Portanto o estudo prévio de qual material utilizar para cada solução desejada e do comportamento previsto para a estrutura segundo projetado são aspectos e indicativos fundamentais que permitem analisar o desempenho do sistema de impermeabilização utilizado ao longo do tempo, determinando assim a sua vida útil e as intervenções necessárias ao longo desse tempo para realizar e atender o que fora projetado.

\section{MATERIAL E MÉTODOS}

\subsection{Caracerísticas do silicato bioquimicamente modificado}

A principal característica do silicato bioquimicamente modificado é reagir quimcamente com o cálcio livre presente na pasta de cimento, produzindo o gel C-S-H, fundamental para manter o concreto são e por possuir um PH igual a 11,7, o silicato bioquimicamente modificado auxilia na manutenção do PH do concreto elevado, mantendo desta forma as condições propícias para a manutenção da passivação das armaduras. Segundo informações e enasios fornecidos pelo fabricante, o silicato bioquimicamente modificado penetra até $20 \mathrm{~mm}$ dentro do concreto e ao longo das fissuras e trincas passivas que por ventura já existam ou venham a ocorrer e ao reagir com o cálcio livre da pasta de cimento, forma o gel C-S-H que tampona os poros vazios e capilares presentes dentro da estrutura física do concreto impermeabilizando-o. Além de impermeabilizar a esturura, esse material ao retirar o cálcio livre de até $20 \mathrm{~mm}$ da sua superfície, acaba por impedir que agentes agressivos do meio ambiente reajam com o hidróxido de cálcio presente na pasta de cimento e iniciem o processo deletério da estrutura de concreto armado. Reações como a lixiviação e a carbonatação necessitam do cálcio para ocorrer e uma vez que o cálcio não esteja disponível ou possua pouco cálcio disponível, essas reações não ocorrem ou ocorrem com uma incidência muito branda.

A reação de formação do gel C-S-H ocorre sempre que a estrutura onde fora aplicado o silicato bioquimicamente modificado entrar em contato com a umidade, haverá então a formação do gel C-S-H, cuja reação química não se desgasta com o passar do tempo e desta forma, há uma proteção contínua. que ao expandir, a formação do gel C-S-H tampona poros vazios e capilares da estrutura interna do concreto armado, impermeabilizando-o e protegendo-o contra diversas agressividades presentes no ambiente. Proporcionando desta forma propriedades regenerativas definitivas (auto-cicatrizantes ativas), uma vez que a formação do gel C-S-H permanece ativa ao entrar em contato com a umidade, permite acompanhar o trabalho realizado pela estrutura de concreto armado, vedando poros, vazios, capilares, fissuras passivas existentes de até $2,0 \mathrm{~mm}$ e, após a realização da aplicação, fissuras passivas de até $0,4 \mathrm{~mm}$. As informações obtidas com o fabricante permitem dizer que realmente é um sistema de proteção e impermeabilização de concreto ativo, ou seja possui uma determinada capacidade de acompanhar as movimentações da estrutura e formar o gel C-S-H enquanto a estrutura assim o permitir, fornecendo assim uma impermeabilização de longo prazo.

Outras características relevantes do silicato bioquimicamente modificado são que este líquido deve ser pulverizado no na estrutura de concreto armado curado, esse material é atóxico, inodoro, é ambientalmente correto, não gera resíduos, não altera a potabilidade da água e aumenta a resistência do concreto em $37 \%$ à ensaios de compressião axial (comparado a um corpo de prova de referência de $25 \mathrm{Mpa}$ ) e a abrasão.

\subsection{Metodologia de execução}

O sistema de impermeabilização, analisado nesse estudo de caso é composto pelo silicato bioquimicamente modificado e os tratamentos pontuais são executados com membrana de poliuretano.

O sistema de impermeabilização utilizando o silicato bioquimicamente modificado necessita da utilização do poliuretano para complementar a estanqueidade nas estruturas que não são de concreto, tais como, alvenaria, blocos, tubulações, complementando assim o sistema de impermeabilização, pois o silicato bioquimicamente modificado somente pode ser utilizado na estrutura de concreto armado, onde reage com o cálcio livre e ao entrar em contato com a umidade forma o gel C-S-H que expande dentro dos poros vazios e capilares da estrutura, de acordo com a composição física interna da estrutura de concreto, pois a expansão do gel C-S-H depende dos poros, vazios e capilares dentro da estrutura de concreto para ter espaço para expandir. 
Desta forma, será apresentado o estudo de caso proposto em um empreendimento residencial situado em Belo Horizonte - MG, com área de aproximadamente $2.250 \mathrm{~m}^{2}$. O acompanhamento da aplicação do sistema de impermeabilização utilizando o silicato bioquimicamente modificado e a membrana de poliuretano como complemento do sistema, foi realizado há mais de três anos, em todas as áreas do pavimento de uso comum do empreendimento residencial, contemplando áreas como: piscina coberta, piscinas descobertas, deck molhado, jardins, quadra de tênis, playground, quadra poliesportiva, áreas de lazer, áreas de uso comum e lajes de cobertura, todas as áreas se encontravam no terceiro pavimento do empreendimento, conforme Figura 1.

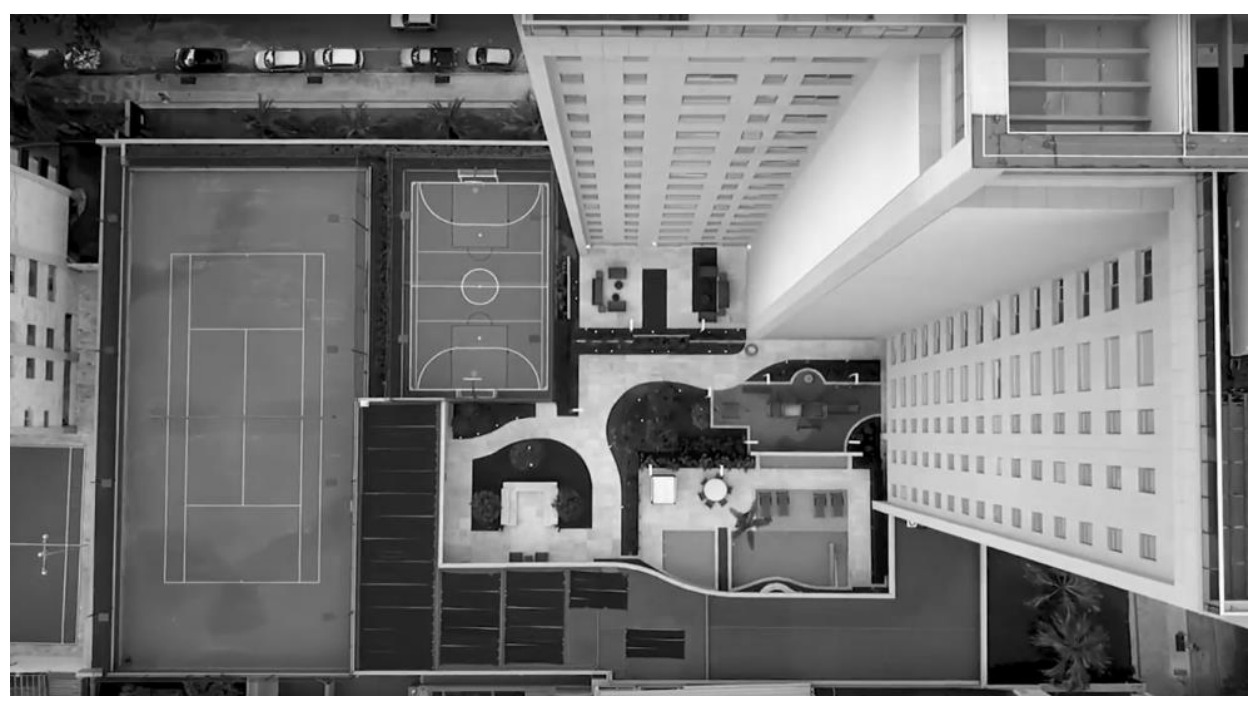

Figura 1 - Foto aérea do empreendimento residencial entregue

A seguir é apresentado a metodologia de aplicação contemplando todas as etapas do sistema de impermeabilização, que foram realizadas no estudo de caso analisado e que estão de acordo com as informações técnicas fornecidas pelo fabricante.

\subsubsection{Preparação da superfíce}

Foi utilizado um soprador para realizar a limpeza superficial de toda a poeira e sedimentos na estrutura, a fim de expor e verificar melhor as fissuras e trincas existentes e identificar todas as interferências presentes e que não pertençam a superfície da estrutura de concreto armado, tais como pontas de prego, madeiras, vergalhões expostos, argamassa ou outro material aderido à estrutura de concreto. Nos casos onde foi identificado alguma camada ou película aderida à superfície de concreto, realizou-se a sua retirada através de polimento e posterior hidrojateamento retirando todo o material ou sujeira aderido à superfície, deixando o concreto isento de materiais contaminantes e preparado para a aplicação do silicato do silicato bioquimicamente modificado.

\subsubsection{Aplicação do silicato bioquimicamente modificado}

A aplicação do silicato bioquimicamente modificado somente pode ser relizada após a estrutura de concreto armado em que será aplicada esteja totalmente seca. Portanto foi necessário aguardar pois a estrutura estava úmida devido ao hidrojateamento realizado na etapa anterior.

O silicato bioquimicamente modificado foi aplicado por pulverização (Figura 2) sobre a superfície da estrutura de concreto armado e utilizou-se uma máquina de airless para sua aplicação. Na aplicação deste material na estrutura foi utilizado um consumo médio de $5 \mathrm{~m}^{2} / 1$, que é o consumo determinado pelo fabricante para que a quantidade de material utilizada tenha o melhor desempenho se incorporando à estrutura. 


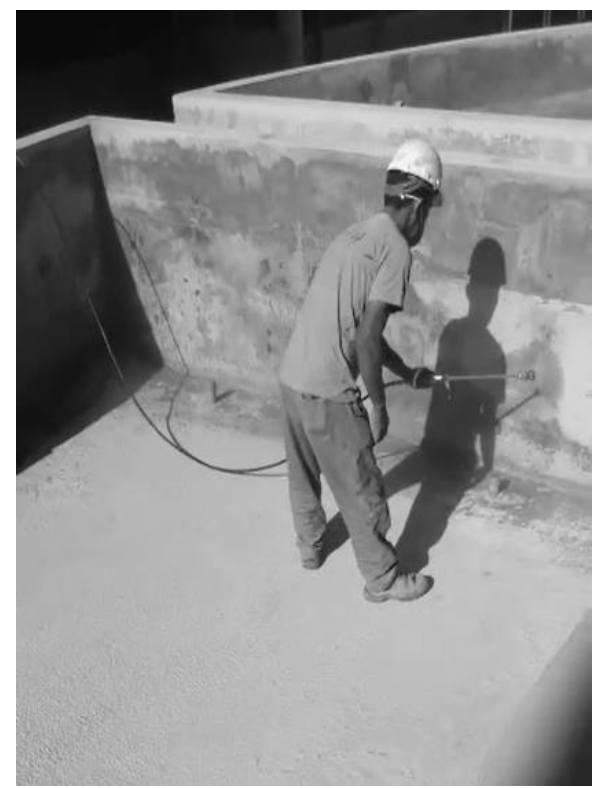

Figura 2- Aplicação por pulverização do silicato bioquimicamente modificado

\subsubsection{Primeira hidratação}

Após o término da aplicação do silicato bioquimicamente modificado, aguardou-se 4 horas, para iniciar o processo de hidratação, onde foi aplicado água abundantemente a uma quantidade mínima de 3 vezes o volume do silicato bioquimicamente modificado aplicado. $\mathrm{O}$ fabricante informa que o tempo em que o silicato bioquimicamente modificado penetra na estrutura de concreto armado pode variar entre 2 a 6 horas, dependendo das condições climáticas. $\mathrm{O}$ indicativo para iniciar a hidratação é que a superfície da estrutura esteja seca aou toque, momento em que se deve iniciar o processo da primeira hidratação.

\subsubsection{Segunda hidratação}

Após 24 horas trasncorridas da primeira hidratação foi realizada a segunda hidratação, aplicando água abundantemente a uma quantidade mínima 3 vezes o volume utilizado na aplicação do silicato bioquimicamente modificado.

\subsubsection{Terceira hidratação}

Após 24 horas transcorridas da segunda hidratação, foi realizada a terceira hidratação, aplicando água abundantemente a uma quantidade mínima de 3 vezes o volume do silicato bioquimicamente modificado aplicado, no local onde está sendo realizado o tratamento.

\subsubsection{Aplicação da membrana de poliuretano}

Após as hidratações do silicato bioquimicamente modificado e a secagem completa da estrutura, foram realizados os tratamentos pontuais com a membrana de poliuretano, que é um material bicomponente e seu consumo utilizado foi de $2 \mathrm{~kg} / \mathrm{m}^{2}$, de acordo com as orientações do fabricante.

Os tratamentos pontuais realizados com a membrana de poliuretano foram em todas as mudanças de planos e detalhes construtivos, incluindo paredes, meia-canas, pilares, ralos, drenos, etc.

A aplicação da membrana de poliuretano obedeceu as seguintes etapas:

- Primeira etapa: Aplicação da primeira demão da membrana de poliuretano.

- Segunda etapa: Entre 6 e 24 horas, após realizada a primeira demão, foi realizada a segunda demão com a aplicação da membrana de poliuretano e assentamento da tela de poliester. 
- Terceira etapa: Entre seis e vinte e quatro horas, após realizada a segunda demão, foi realizada a aplicação da terceira demão da membrana de poliuretano, a fim de cobrir completamente a tela de poliester assentada na segunda demão.

- Quarta etapa: Entre seis e vinte e quatro horas, após realizada a terceira demão, foi verificado se toda a aplicação da membrana de poliuretano está sem bolhas ou vazios e se a tela de poliester está totalmente coberta pela membrana de poliuretano. Nos casos onde isso não ocorreu, foi utilizado nova demão da membrana de poliuretano para regularizar a aplicação e cobrir totalmente a tela de poliester.

A altura de utilização da membrana de poliuretano em todos os planos verticais de interface do concreto com outro material, como por exemplo na alvenaria de fechamento da periferia do empreendimento, não pode ser menor que $20 \mathrm{~cm}$ de altura (NBR 9575, 2010), de acordo com o apresentado na Figura 3.



Figura 3 - Utilização da membrana de poliuretano na alvenaria de fechamento

\subsubsection{Teste de estanqueidade}

Após a conclusão da impermeabilização, foi realizado o teste de estanqueidade de 72 horas, que é o que o fabricante e a NBR 9575 (2010) recomendam como período mínimo de teste de estanqueidade, entretanto, o fabricante recomenda deixar a área em carga com água, o máximo de tempo possível, se possível uma semana de teste de estanqueidade. Isso porque quanto maior for o tempo de contato da água com o silicato bioquimicamente modificado, maior será o estímulo na sua reação e incorporação junto à estrutura de concreto, acelerando suas características e seu desempenho com a proteção e impermeabilização da estrutura de concreto armado.

Nos casos onde o teste de estanqueidade obedecem as 72 horas, o fabricante informa que o resultado final da incorporação do silicato bioquimicamente modificado será o mesmo que realizar um teste de estanqueidade de uma semana, entretanto o resultado completo da incorporação desse material na estrutura de concreto armado levará mais tempo, pois o resultado dessa reação química é acelerado quanto maior for o tempo de contato com a água.

\section{RESULTADOS E DISCUSSÕES}

A reação de impermeabilização do silicato bioquimicamente modificado incorporado à estrutura de concreto armado através da formação do gel C-S-H, alia a necessidade de impermeabilização da estrutura com a sua proteção, através de benefícios como redução na fissuração, aumento da resistência à compressão axial, impedindo a eflorescência e carbonatação, devido a retirada do cálcio livre presente até os $20 \mathrm{~mm}$ de profundidade da superfície de concreto.

Além dessas proteções, o silicato bioquimicamente modificado possui um PH de 11,7 que mantém o concreto com certa alcalinidade, protegendo também a estrutura de concreto quanto aos principais agentes deletérios presentes no ambiente. A utilização da membrana de poliuretano no sistema de impermeabilização estudado possui um papel complementar nas interfaces que ocorrem junto à estrutura de concreto armado que não são de concreto, como a junção entre a alvenaria de fechamento do empreendimento com a laje, tubulações passantes, ralos, onde deve-se impermeabilizar a interface entre a tubulação de PVC e a estrutura de concreto. Para todas essas interfaces esse sistema de impermeabilização utiliza uma membrana de poliuretano de modo a garantir a estanqueidade entre os diferentes materiais que possuam interface com a estrutura de concreto, conforme apresentado na Figura 4. 


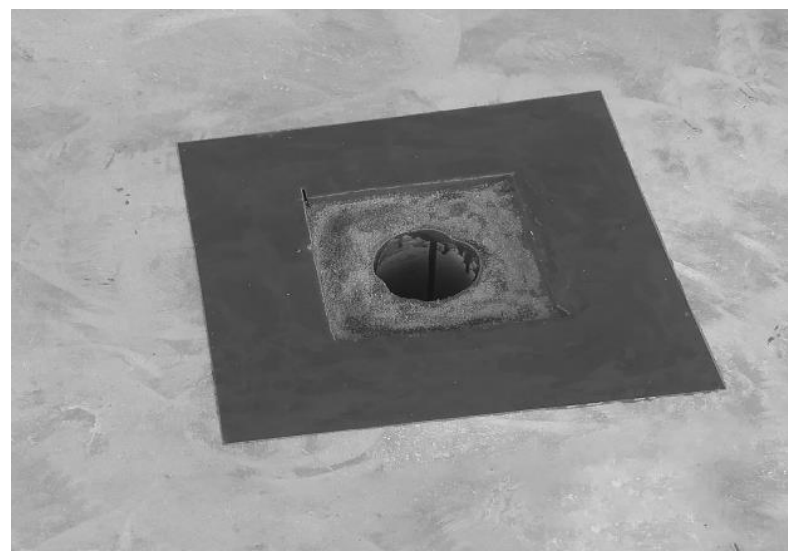

Figura 4 - Utilização da membrana de poliuretano no encontro da estrutura com o ralo

A Figura 5 apresenta a foto de algumas áreas que foram tratadas com a aplicação do silicato bioquimicamente modificado, contemplando áreas como, piscinas, deck molhado, jardins, quadra de tênis, quadra poliesportiva, áreas de lazer e áreas de uso comum.

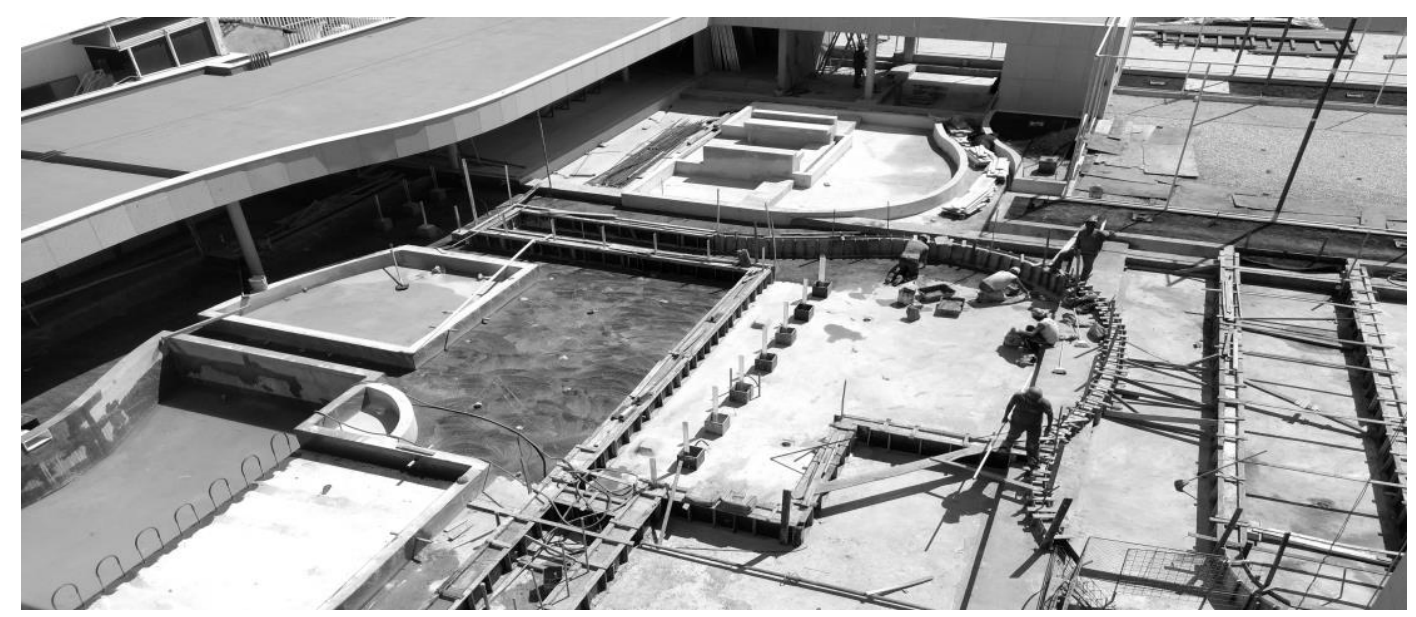

Figura 5 - Áreas com aplicação do silicato bioquimicamente modificado

Normalmente a grande maioria dos sistemas de impermeabilização é executada no final da obra, entretanto uma das características desse sistema de impermeabilização é poder e preferencialmente dever ser aplicado o quanto antes após a cura do concreto, pois desta forma, a sua incorporação à estrutura permitirá e trará benefícios protetivos, como aumento da resistência à compressão, redução na fissuração, mitigação de possíveis lixiviações e carbonatações na estrutura de concreto, entre outros.

Outra vantagem sensível para a utilização desse sistema de impermeabilização é que ao aplicá-lo logo após a cura do concreto, antecipa-se a etapa de impermeabilização no cronograma da obra e otbém-se as características protetivas do silicato bioquimicamente modificado pelo transcorrer do restante da obra, que pode durar de alguns meses ou até mesmo anos até o empreendimento ser entregue para o proprietário. Durante todo esse prazo até a entrega do empreendimento, a impermeabilização é testada, mitigando qualquer necessidade de manutenção após a entrega do empreendimento.

Quando se utiliza um sistema de impermeabilização que necessita de proteção mecânica e quando ocorre algum vazamento, normalmente há uma dificuldade da identificação da origem do problema, uma vez que a água percola por baixo da impermeabilização aflorando em outro ponto. Outro fator relevante quando isso ocorre é a necessidade da retirada da proteção mecânica, gerando resíduos, que devem ser descartados apropriadamente, além de gerar grandes transtornos aos proprietários, pois isso influenciará na utilização dos espaços do empreendimento que não poderão ser 
utilizados enquanto a manutenção estiver sendo executada. Muitas das vezes, alguns proprietários acabam tendo que estacionar seus veículos em outros locais para liberar a área onde será feita a intervenção.

No caso do sistema apresentado, onde a estrutura fica aparente, qualquer manutenção é extremamente mais simples, praticamente sem geração de resíduos e qualquer vazamento que ocorra possui uma identificação de sua localização e manutenção muito mais simples que as impermeabilizações com membrana e proteção mecânica.

Esse sistema é amplamente utilizado no mercado mundial, protegendo e impermeabilizando estruturas de concreto há mais de 40 anos, podendo ser aplicado nas diversas estruturas de concreto armado, aparentes ou com revestimento. No caso de uma estrutura aparente, esse sistema permite que o trabalho da estrutura que por ventura aconteça seja monitorado visualmente. Já no caso da estrutura estar coberta com a proteção mecânia, não é possível verificar o trabalho da estrutura de concreto armado, somente quando a mesma trabalhar de forma que os esforços sejam tranferidos para a membrana de impermeabilização e posteriormente para a proteção mecância, que ai sim será possivel identificar visualmente na parte superior da estrutura as fissuras e trincas que estão ocorrendo na estrutura de concreto armado e sendo transferidas para a parte superior do pavimento exposto.

\section{CONCLUSÕES}

Segundo informações do fabricante, no Brasil, o silicato bioquimicamente modificado já protegeu e impermeabilizou mais de um milhão de metros quadrados, ao longo de mais de 20 anos de atuação no país e no estudo de caso em questão não houve nenhum retorno ou necessidade de manutenção nesse empreendimento até a presente data.

Há uma necessidade veemente por parte dos projetistas no país por soluções de impermeabilização que possuam uma vida útil de longo prazo, pois segundo a NBR 15.575 (2013), as impermeabilizações de áreas internas, de piscina, de áreas externas com pisos, áreas de garagem, rampas, dentre outras áreas, necessitam de um projeto que contemple uma vida útil mínima de 20 anos, vida útil ideal de 25 anos e vida útil máxima de 30 anos. Dito isso, poucos são os sistemas de impermeabilização que conseguem atender essa vida útil, e a utilização do sistema de impermeabilização com a aplicação o silicato bioquimicamente modificado na estrutura de concreto armado se faz presente atendendo essa necessidade, pois, uma vez que essa solução está incorporada ao concreto e a sua reação química de formação do gel CS-H não se desgasta com o passar do tempo, a vida útil do gel C-S-H se torna a vida útil da estrutura em si, obedecendo a vida útil necessária na NBR 15.575.

Portanto, esse estudo de caso recomenda que ocorram outros estudos relacionados à atuação do silicato bioquimicamente modificado na impermeabilização e proteção de estruturas de concreto armado, pois em um primeiro momento, essa solução traz diversos benefícios para os empreendimentos residenciais e comerciais, resolvendo um problema que é constante na construção civil, o efeito deletério da água e agentes agressivos do ambiente nas estruturas de concreto armado.

\section{REFERÊNCIAS}

ASSOCIAÇÃO BRASILEIRA DE NORMAS TÉCNICAS. NBR 9574 - Execução de impermeabilização. Rio de Janeiro, 2008.

ASSOCIAÇÃO BRASILEIRA DE NORMAS TÉCNICAS. NBR 9575 - Impermeabilização -Seleção e projeto. Rio de Janeiro, 2010.

ASSOCIAÇÃO BRASILEIRA DE NORMAS TÉCNICAS. NBR 12170: Materiais de impermeabilização: potabilidade de água aplicável em sistemas de impermeabilização. Rio de Janeiro. 1992.

ASSOCIAÇÃO BRASILEIRA DE NORMAS TÉCNICAS. NBR 12171: Aderência aplicável em sistema de impermeabilização composto por cimento impermeabilizante e polímeros - Método de ensaio. Rio de janeiro, 2018.

ASSOCIAÇÃO BRASILEIRA DE NORMAS TÉCNICAS. NBR 15575 - Edificações habitacionais - Desempenho. Parte 5: Requisitos para sistemas de coberturas, 2013. 


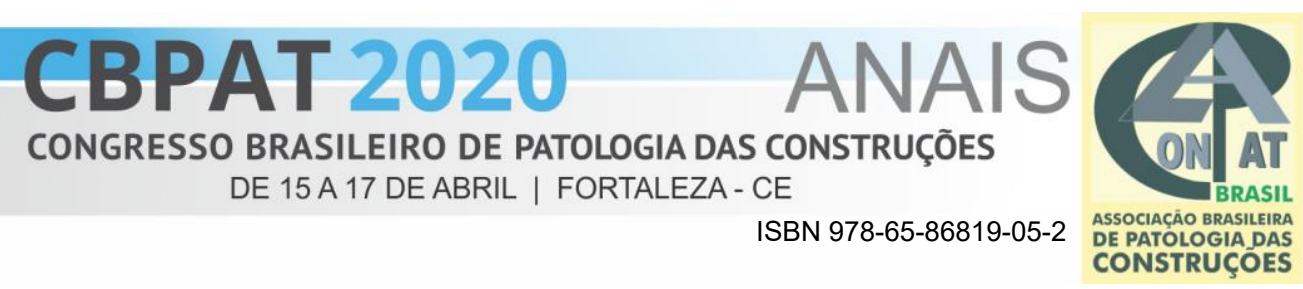

HELENE, Paulo. A nova NB 1/2003 (NBR 6118) ea vida útil das estruturas de concreto. University of Sao Paulo PCC USP, 2003.

MOREIRA, Heloisa Pimentel; FIGUEIREDO, Enio Pazini; HELENE, Paulo RL. Avaliação da influência de alguns agentes agressivos na resistência à compressão de concretos amassados com diferentes tipos de cimentos brasileiros. EPUSP, 2001.

QUERUZ, F. Contribuição para indentificação dos principais agentes e mecanismos de degradação em edificações da Vila Belga.Santa Maria: UFSM, 2007. 150 p. Dissertação (Mestrado em Engenharia Civil) - Universidade Federal de Santa Maria, 2007.

RIGHI, V. G. Estudos dos sistemas de impermeabilização: Patologias, prevenções e correções - Análise de casos. Dissertação de Mestrado em Engenharia Civil. Universidade Federal de Santa Maria. Santa Maria, 2009.

SOUZA, M. F. Patologias ocasionadas pela umidade nas edificações. 2008. 64 f. Monografia (Especialização) - Curso de Curso de Especialização em Construção Civil, Universidade Federal de Minas Gerais, Belo Horizonte, 2008. 